九州大学学術情報リポジトリ

Kyushu University Institutional Repository

Introducing Viewpoints of Mechanics into Basic Growth Analysis : (VIII) Applying Basic Growth Mechanics to Ruminants, Forages and Related Problems

Shimojo, Masataka

Laboratory of Animal Feed Science, Division of Animal Science, Department of Animal and Marine Bioresource Sciences, Faculty of Agriculture, Kyushu University

Youssef, Mohamed Farid

Department of Animal Production, Faculty of Agriculture, Kafrelsheikh University

Masuda, Yasuhisa

Emeritus Professor of Kyushu University

https://doi.org/10.5109/14048

出版情報：九州大学大学院農学研究院紀要. 54 (1)，pp. 133-136，2009-02-27. Faculty of Agriculture, Kyushu University

バージョン：

権利関係 : 


\title{
Introducing Viewpoints of Mechanics into Basic Growth Analysis - (VIII) Applying Basic Growth Mechanics to Ruminants, Forages and Related Problems -
}

\author{
Masataka SHIMOJO*, Mohamed Farid Youssef \\ and Yasuhisa MASUDA ${ }^{1}$
}

\author{
Laboratory of Animal Feed Science, Division of Animal Science, Department of Animal and Marine Bioresource Sciences, \\ Faculty of Agriculture, Kyushu University, Fukuoka 812-8581, Japan \\ and Department of Animal Production, Faculty of Agriculture, \\ Kafrelsheikh University, Egypt \\ (Received November 14, 2008 and accepted December 5, 2008)
}

\begin{abstract}
This study was conducted to investigate the way of calculation in the application of basic growth mechanics to the ruminant animal, the forage plant, indigestibility increase with forage growth and net assimilation rate of the forage plant. The results obtained were as follows. (1) The mean value over the given interval for absolute growth rate of weight (AGRw) was described using the product of mean weight ( $W$ ) and mean growth acceleration of $W(\mathrm{GAw})$. (2) The mean value over the given interval for AGRi (AGR of indigestible matter $(I)$ ) was described using the product of mean value of $I$ and that of GAi (GA of $I$ ). (3) The indigestibility increase with forage growth, which was given by two different descriptions, was described using mean value over the given interval for $I$, that for GAi, that for $W$ and that for GAw. (4) The mean value over the given interval for net assimilation rate (NAR) of the forage plant was described using mean leaf area $(A)$, mean $W$ and mean GAw. It was suggested that applying basic growth mechanics gave a unified viewpoint to concepts of analyzing the ruminant animal growth, the forage plant growth, indigestibility increase with forage growth and net assimilation rate of the forage plant.
\end{abstract}

\section{INTRODUCTION}

Shimojo et al. (2006, 2007a, 2007b, 2008) introduced viewpoints of mechanics into basic growth analysis of the ruminant animal (Brody, 1945; Shimojo et al., 1997) and the forage plant (Blackman, 1919; Watson, 1952; Radford, 1967; Hunt, 1990). This suggests a differential equation that describes absolute growth rate using the square root of the product of weight and growth acceleration. However, we did not show the way of calculation when applied to the actual data collected from growth experiments of the ruminant and the forage. The growth of ruminant animal depends mainly on intake of digestible materials in the forage plant. It is well known that there is an increase in the weight of indigestible materials with the growth of forage, which causes the decrease in forage digestibility. Therefore, analyzing the process of forage growth and indigestibility increase gives useful information to the development of forage-based ruminant agriculture from the viewpoint of supplying the high quality forage to the ruminant.

The present study was designed to investigate the way of calculation in the application of basic growth mechanics to the ruminant animal, the forage plant, indigestibility increase with forage growth and net assimilation rate of the forage plant.

1 Emeritus Professor of Kyushu University

* Corresponding author (E-mail: mshimojo@agr.kyushu-u.ac.jp)
APPLYING GROWTH MEHCHANICS TO THE RUMINANT ANIMAL, THE FORAGE PLANT AND RELATED PROBLEMS

\section{(A) Basic growth mechanics}

Shimojo et al. (2006, 2007a, 2007b, 2008) suggested basic growth mechanics using a series of the following calculations. Thus,

$$
\begin{aligned}
& (1 / W) \cdot(d W / d t)=\mathrm{RGRW}, \\
& W=W_{0} \cdot \exp (\mathrm{RGRw} \cdot t),
\end{aligned}
$$

where $W=$ weight of the ruminant animal or the forage plant at time $t, \mathrm{RGRW}=$ relative growth rate of $W, W_{\mathbf{0}}=$ weight at $t=0$.

Then,

$$
\begin{aligned}
& \mathrm{AGRW}=d W / d t=\mathrm{RGRW} \cdot W_{\mathbf{0}} \cdot \exp (\mathrm{RGRW} \cdot t), \\
& \mathrm{GAw}=d^{2} W / d t^{2}=(\mathrm{RGRW})^{2} \cdot W_{\mathbf{0}} \cdot \exp (\mathrm{RGRw} \cdot t),
\end{aligned}
$$

where AGRw=absolute growth rate of $W$, GAw=growth acceleration of $W$.

Relating functions (2) (4) gives

$$
\begin{aligned}
& (\mathrm{AGRw} / W)=(\mathrm{GAw} / \mathrm{AGRw})=\mathrm{RGRw}, \\
& (\mathrm{AGRw})^{2}=W \cdot \mathrm{GAw} .
\end{aligned}
$$

Function (6) shows that AGRw is equal to the product of $W$ and GAw. This relation has an analogy with Newton's equation of motion (Kawabe, 2006), where force $(F)$ is described as the product of mass $(m)$ of an object and 
acceleration ( $a$ ), namely $F=m \cdot a$. Thus, the left-hand side of function (6) might be regarded as growth force.

The mean value over the interval $t_{1}$ to $t_{2}$ is calculated for the three terms of function (6) using actual data. The ways of calculation of them are given by,

$$
\begin{aligned}
& \overline{\mathrm{AGRW}}=\frac{W_{2}-W_{1}}{t_{2}-t_{1}}, \\
& \bar{W}=\frac{W_{2}-W_{1}}{\log _{\mathrm{e}} W_{2}-\log _{\mathrm{e}} W_{1}}, \\
& \overline{\mathrm{GAW}}=\frac{\mathrm{GAW}_{2}-\mathrm{GAW}_{1}}{\log _{\mathrm{e}} \mathrm{GAW}_{2}-\log _{\mathrm{e}} \mathrm{GAW}_{1}}, \\
& =\frac{\mathrm{AGRW}_{2}-\mathrm{AGRW}_{1}}{t_{2}-t_{1}} .
\end{aligned}
$$

Expression (10) is the definition of $\overline{\mathrm{GAw}}$, and it is also given by expression (9) in basic growth mechanics. Thus, combining expressions (6) (10) gives

$$
\begin{aligned}
& \overline{\mathrm{AGRW}}=\sqrt{\bar{W} \cdot \overline{\mathrm{GAW}}}, \\
& \frac{W_{2}-W_{1}}{t_{2}-t_{1}}=\sqrt{\frac{W_{2}-W_{1}}{\log _{\mathrm{e}} W_{2}-\log _{\mathrm{e}} W_{1}} \cdot \frac{\mathrm{GAW}_{2}-\mathrm{GAW}_{1}}{\log _{\mathrm{e}} \mathrm{GAW}_{2}-\log _{\mathrm{e}} \mathrm{GAW}_{1}}},
\end{aligned}
$$

$$
=\sqrt{\frac{W_{2}-W_{1}}{\log _{\mathrm{e}} W_{2}-\log _{\mathrm{e}} W_{1}} \cdot \frac{\mathrm{AGRW}_{2}-\mathrm{AGRW}_{1}}{t_{2}-t_{1}}} .
$$

Expressions (12) and (13) show that mean AGRw over the interval $t_{\mathbf{1}}$ to $t_{\mathbf{2}}$ is evaluated by two components that are mean $W$ and mean GAw. It is, therefore, interesting to investigate relationships between $W$ and GAw, namely how the size of $W$ influences GAw. This has an analogy with the issue of motion: how the mass size of an object affects its acceleration (Kawabe, 2006). When $W$ of the ruminant animal or the forage plant is large, high GAw is required to get high AGRw. GAw is related to many animal or plant factors: feed intake and digestibility, animal breeds and other factors for the ruminant animal, and light receiving ability of leaves, nutrients absorption ability of roots and other factors for the forage plant.

\section{(B) Applying basic growth mechanics to formation of forage indigestible matter}

Basic growth mechanics for forage indigestible matter is given by a series of the following calculations. Thus,

$$
I=I_{0} \cdot \exp (\mathrm{RGRi} \cdot t)
$$

where $I=$ indigestible matter weight of the forage plant at time $t, I_{0}=$ forage indigestible matter weight at $t=0$, RGRi=relative growth rate of $I$.

Then,

$$
\begin{aligned}
& \mathrm{AGRi}=d I / d t=\mathrm{RGRi} \cdot I_{0} \cdot \exp (\mathrm{RGRi} \cdot t), \\
& \mathrm{GAi}=d^{2} I / d t^{2}=(\mathrm{RGRi})^{2} \cdot I_{0} \cdot \exp (\mathrm{RGRi} \cdot t),
\end{aligned}
$$

where $\mathrm{AGRi}=$ absolute growth rate of $I, \mathrm{GAi}=$ growth acceleration of $I$.

Relating functions (14) (16) gives

$$
\begin{aligned}
& (\text { AGRi } / I)=(\text { GAi } / \text { AGRi })=\text { RGRi }, \\
& (\text { AGRi })^{2}=I \cdot \text { GAi. }
\end{aligned}
$$

The mean value over the interval $t_{1}$ to $t_{2}$ is calculated for the three terms of function (18) using actual data of the forage plant. The ways of calculation of them are given by,

$$
\begin{aligned}
\overline{\mathrm{AGRi}}=\frac{I_{2}-I_{1}}{t_{2}-t_{1}}, \\
\bar{I}=\frac{I_{2}-I_{1}}{\log _{\mathrm{e}} I_{2}-\log _{\mathrm{e}} I_{1}}, \\
\overline{\mathrm{GAi}}=\frac{\mathrm{GAi}_{2}-\mathrm{GAi}_{1}}{\log _{\mathrm{e}} \mathrm{GAi}_{2}-\log _{\mathrm{e}} \mathrm{GAi}_{1}}, \\
=\frac{\mathrm{AGRi}_{2}-\mathrm{AGRi}_{1}}{t_{2}-t_{1}} .
\end{aligned}
$$

Thus, combining expressions (18) (22) gives

$$
\begin{aligned}
& \overline{\mathrm{AGRi}}=\sqrt{\bar{I} \cdot \overline{\mathrm{GAi}}}, \\
& \frac{I_{2}-I_{1}}{t_{2}-t_{1}}=\sqrt{\frac{I_{2}-I_{1}}{\log _{\mathrm{e}} I_{2}-\log _{\mathbf{e}} I_{1}} \cdot \frac{\mathrm{GAi}_{2}-\mathrm{GAi}_{1}}{\log _{\mathrm{e}} \mathrm{GAi}_{2}-\log _{\mathrm{e}} \mathrm{GAi}_{1}}}, \\
&=\sqrt{\frac{I_{2}-I_{1}}{\log _{\mathbf{e}} I_{2}-\log _{\mathbf{e}} I_{1}} \cdot \frac{\mathrm{AGRi}_{2}-\mathrm{AGRi}_{1}}{t_{2}-t_{1}}} .
\end{aligned}
$$

When the forage plant has large $I$, high AGRi requires high GAi. GAi is related to maturing of the forage plant such as lignification and silicification of plant fiber fractions and high ratio of stem to leaf. However, this reduces forage utilization by ruminants, anti-quality characteristics of the plant.

\section{(C) Applying basic growth mechanics of forage indigestible matter formation to indigestibility increase with forage growth}

Investigating indigestibility is recommended to analyze forage digestion characteristics, because there is usually a continuous increase of indigestible matter weight with forage growth compared with digestible matter weight that often shows a decrease when the forage matures. We take up two types of functions that describe indigestibility increase with forage growth: function (26) suggested by Masuda (1985) and function (27) suggested by Shimojo et al. (1995). Both func- 
tions were compared and related by Shimojo et al. (1998). Thus,

$$
\begin{aligned}
& \frac{I_{2}}{W_{2}}-\frac{I_{1}}{W_{1}}=\frac{I_{1}}{W_{1}} \cdot\left[\exp \left((\overline{\mathrm{RGRi}}-\overline{\mathrm{RGRW}}) \cdot\left(t_{2}-t_{1}\right)\right)-1\right], \\
& \frac{I_{2}}{W_{2}}-\frac{I_{1}}{W_{1}}=\left(1-\frac{I_{1}}{W_{1}}\right) \cdot\left(\frac{\overline{\mathrm{AGRi}}}{\overline{\mathrm{AGRW}}}-\frac{I_{1}}{W_{1}}\right) .
\end{aligned}
$$

(C-1) Analyzing indigestibility increase using function (26)

RGRw in function (26) is replaced with RGAw according to a series of the following procedures. Thus,

$$
\begin{aligned}
& (\text { AGRw })^{2}=W \cdot \text { GAw, } \\
& (d W / d t)^{2}=W \cdot\left(d^{2} W / d t^{2}\right), \\
& (1 / W) \cdot(d W / d t)=\sqrt{(1 / W) \cdot\left(d^{2} W / d t^{2}\right)}, \\
& \text { RGRW }=\sqrt{\mathrm{RGAW}},
\end{aligned}
$$

where RGRw=relative growth rate of $W$, RGAw=relative growth acceleration of $W$.

Likewise, applying these procedures to $I$ gives

$$
\begin{aligned}
& (1 / I) \cdot(d I / d t)=\sqrt{(1 / I) \cdot\left(d^{2} I / d t^{2}\right)}, \\
& \text { RGRi }=\sqrt{\text { RGAi }},
\end{aligned}
$$

where RGRi=relative growth rate of $I, \mathrm{RGAi}=$ relative growth acceleration of $I$.

The mean value over the interval $t_{1}$ to $t_{\mathbf{2}}$ for functions (30) and (32) are given by

$$
\overline{\mathrm{RGRw}}=\sqrt{\overline{\mathrm{RGAw}}}, \quad \overline{\mathrm{RGRi}}=\sqrt{\overline{\mathrm{RGAi}}} .
$$

Therefore,

$$
\begin{aligned}
\overline{\mathrm{RGRW}} & =\frac{\log _{\mathrm{e}} W_{2}-\log _{\mathrm{e}} W_{1}}{t_{2}-t_{1}} \\
& =\sqrt{\frac{\log _{\mathbf{e}} W_{2}-\log _{\mathbf{e}} W_{1}}{W_{2}-W_{1}} \cdot \frac{\mathrm{GAW}_{2}-\mathrm{GAW}_{1}}{\log _{\mathbf{e}} \mathrm{GAW}_{2}-\log _{\mathbf{e}} \mathrm{GAW}_{1}}}, \\
& =\sqrt{\frac{\log _{\mathbf{e}} W_{2}-\log _{\mathbf{e}} W_{1}}{W_{2}-W_{1}} \cdot \frac{\mathrm{AGRW}_{2}-\mathrm{AGRW}_{1}}{t_{2}-t_{1}}} \cdot(35) \\
& =\sqrt{\frac{\log _{\mathbf{e}} I_{2}-\log _{\mathbf{e}} I_{1}}{t_{2}-t_{1}}} \\
& =\sqrt{\frac{\log _{\mathbf{e}} I_{2}-\log _{\mathbf{e}} I_{1}}{I_{2}-I_{1}} \cdot \frac{\log _{\mathbf{e}} I_{2}-\log _{\mathbf{e}} I_{1}}{I_{2}-I_{1}} \cdot \frac{\mathrm{GAi}_{2}-\mathrm{GAi}_{1}}{\log _{\mathbf{e}} \mathrm{GAi}_{2}-\log _{\mathrm{e}} \mathrm{GAi}_{1}-\mathrm{AGRi}_{1}}},
\end{aligned}
$$

Using functions (34) (37), function (26) is rewritten by two ways of description as follows,

$$
\begin{gathered}
\frac{I_{2}}{W_{2}}-\frac{I_{1}}{W_{1}}=\frac{I_{1}}{W_{1}} \cdot\left[\exp \left((\sqrt{\overline{\mathrm{RGAi}}}-\sqrt{\mathrm{RGAW}}) \cdot\left(t_{2}-t_{1}\right)\right)-1\right] \\
=\frac{I_{1}}{W_{1}} \cdot\left[\operatorname { e x p } \left(\left(\sqrt{\frac{\log _{\mathbf{e}} I_{2}-\log _{\mathbf{e}} I_{1}}{I_{2}-I_{1}} \cdot \frac{\mathrm{GAi}_{2}-\mathrm{GAi}_{1}}{\log _{\mathbf{e}} \mathrm{GAi}_{2}-\log _{\mathbf{e}} \mathrm{GAi}_{1}}}\right.\right.\right. \\
-\sqrt{\left.\frac{\log _{\mathbf{e}} W_{2}-\log _{\mathbf{e}} W_{1}}{W_{2}-W_{1}} \cdot \frac{\mathrm{GAW}_{\mathbf{2}}-\mathrm{GAW}_{\mathbf{1}}}{\log _{\mathbf{e}} \mathrm{GAW}_{\mathbf{2}}-\log _{\mathbf{e}} \mathrm{GAW}_{1}}\right)} \\
\left.\left.\cdot\left(t_{2}-t_{1}\right)\right)-1\right],
\end{gathered}
$$$$
=\frac{I_{1}}{W_{1}} \cdot\left[\operatorname { e x p } \left(\left(\sqrt{\frac{\log _{\mathbf{e}} I_{2}-\log _{\mathbf{e}} I_{1}}{I_{2}-I_{1}} \cdot \frac{\mathrm{AGRi}_{2}-\mathrm{AGRi}_{1}}{t_{2}-t_{1}}}\right.\right.\right.
$$$$
\left.-\sqrt{\frac{\log _{\mathrm{e}} W_{2}-\log _{\mathrm{e}} W_{1}}{W_{2}-W_{1}} \cdot \frac{\mathrm{AGRW}_{2}-\mathrm{AGRW}_{1}}{t_{2}-t_{1}}}\right)
$$$$
\left.\left.\cdot\left(t_{2}-t_{1}\right)\right)-1\right]
$$

(C-2) Analyzing indigestibility increase using function (27)

Likewise, function (27) is rewritten by two ways of description as follows,

$$
\begin{aligned}
& \left.\frac{I_{2}}{W_{2}}-\frac{I_{1}}{W_{1}}=\left(1-\frac{W_{1}}{W_{1}}\right) \cdot \frac{\sqrt{\bar{I} \cdot \overline{\mathrm{GAi}}}}{\sqrt{\bar{W} \cdot \overline{\mathrm{GAW}}}}-\frac{I_{1}}{W_{1}}\right) \\
& =\left(1-\frac{W_{1}}{W_{2}}\right) \cdot\left(\frac{\sqrt{\frac{I_{2}-I_{1}}{\log _{\mathrm{e}} I_{2}-\log _{\mathrm{e}} I_{1}} \cdot \frac{\mathrm{GAi}_{2}-\mathrm{GAi}_{1}}{\log _{\mathrm{e}} \mathrm{GAi}_{2}-\log _{\mathrm{e}} \mathrm{GAi}_{1}}}}{\sqrt{\frac{W_{2}-W_{1}}{\log _{\mathrm{e}} W_{2}-\log _{\mathrm{e}} W_{1}} \cdot \frac{\mathrm{GAW}_{2}-\mathrm{GAW}_{1}}{\log _{\mathrm{e}} \mathrm{GAW}_{2}-\log _{\mathrm{e}} \mathrm{GAW}_{1}}}}\right. \\
& \left.-\frac{I_{1}}{W_{1}}\right) \\
& =\left(1-\frac{W_{1}}{W_{2}}\right) \cdot\left(\frac{\sqrt{\frac{I_{2}-I_{1}}{\log _{\mathrm{e}} I_{2}-\log _{\mathrm{e}} I_{1}} \cdot \frac{\mathrm{AGRi}_{2}-\mathrm{AGRi}_{1}}{t_{2}-t_{1}}}}{\sqrt{\frac{W_{2}-W_{1}}{\log _{\mathrm{e}} W_{2}-\log _{\mathrm{e}} W_{1}} \cdot \frac{\mathrm{AGRW}_{2}-\mathrm{AGRW}_{1}}{t_{2}-t_{1}}}}\right. \\
& \left.-\frac{I_{1}}{W_{1}}\right)
\end{aligned}
$$

Functions (38) (41) show that indigestibility increase with forage growth over the interval $t_{1}$ to $t_{2}$ is evaluated by four components: mean $W$, mean $I$, mean GAw and mean GAi. It is, therefore, interesting to investigate how the size of $W$ influences GAw and how the size of $I$ influences GAi. 
(D) Applying basic growth mechanics to net assimilation rate of the forage plant

Since leaf area plays an important role in the plant growth, the simple growth analysis of the forage plant is usually given by

$$
(1 / W) \cdot(d W / d t)=(1 / A) \cdot(d W / d t) \cdot(A / W)
$$

where $A=$ leaf area of the forage plant, $(1 / A) \cdot(d W / d t)=$ net assimilation rate $(\mathrm{NAR}),(A / W)=$ leaf area ratio (LAR)

Combining differential equations (42) and (29) gives

$$
\sqrt{(1 / W) \cdot\left(d^{2} W / d t^{2}\right)}=\left\{(1 / A) \cdot \sqrt{W \cdot\left(d^{2} W / d t^{2}\right)}\right\} \cdot(A / W),
$$

where the expression in braces in the right-hand side gives NAR.

The mean value of NAR over the interval $t_{\mathbf{1}}$ to $t_{\mathbf{2}}$ in function (43) is given by

$$
\begin{aligned}
\overline{\mathrm{NAR}}= & \frac{\log _{\mathrm{e}} A_{2}-\log _{\mathrm{e}} A_{1}}{A_{2}-A_{1}} \\
& \cdot \sqrt{\frac{W_{2}-W_{1}}{\log _{\mathrm{e}} W_{2}-\log _{\mathrm{e}} W_{1}} \cdot \frac{\mathrm{GAW}_{2}-\mathrm{GAW}_{1}}{\log _{\mathrm{e}} \mathrm{GAW}_{2}-\log _{\mathrm{e}} \mathrm{GAW}_{1}}}, \\
= & \frac{\log _{\mathrm{e}} A_{2}-\log _{\mathrm{e}} A_{1}}{A_{2}-A_{1}} \\
& \cdot \sqrt{\frac{W_{2}-W_{1}}{\log _{\mathrm{e}} W_{2}-\log _{\mathrm{e}} W_{1}} \cdot \frac{\mathrm{AGRW}_{2}-\mathrm{AGRW}_{1}}{t_{2}-t_{1}}}
\end{aligned}
$$

\section{(E) Conclusions}

It is suggested from the present study that applying basic growth mechanics gives a unified viewpoint to concepts of analyzing the ruminant animal growth, the forage plant growth, indigestibility increase with forage growth and net assimilation rate of the forage plant.

\section{REFERENCES}

Blackman, V. H. 1919 The compound interest law and plant growth. Ann. Bot., 33: 353-360

Brody, S. 1945 Time relations of growth of individuals and populations. In "Bioenergetics and Growth - with special reference to the efficiency complex in domestic animals", Reinhold Publishing Corporation, New York, pp. 484-574

Hunt, R. 1990 Basic Growth Analysis. Unwin Hyman Ltd., London.

Kawabe, T. 2006 Standard Mechanics. Shokabo Publishing Co., Ltd., Tokyo. (written in Japanese)

Masuda, Y. 1985 Analysis of dry matter digestibility of green panic as affected by the change in temperature. Proc. XV Int. Grassl. Congr., 1009-1011

Radford, P. J. 1967 Growth analysis formulae-their use and abuse. Crop Sci., 7: 171-175

Shimojo, M., Y. Masuda, T. Bungo, T. Kawamura and I. Goto 1995 Analytical expression for formation of indigestible materials and increase in dry matter indigestibility with growth of some tropical grasses. J. Fac. Agr., Kyushu Univ., 40: $179-188$

Shimojo, M., T. Bungo, Y. Imura, M. Tobisa, N. Koga, Y. Nakano, I Goto and Y. Masuda 1997 Relative growth rate of beef cattle expressed using factors related to feed intake, maintenance requirements and feed efficiency. J. Fac. Agr., Kyushu Univ., 42: 87-93

Shimojo, M., T. Bungo, Y. Imura, M. Tobisa, N. Koga, S. Tao, M. Yunus, Z. Yin, Y. Nakano, I. Goto and Y. Masuda 1998 Relationship between two different-type equations analyzing increase in dry matter indigestibility with growth of forages. J. Fac. Agr., Kyushu Univ., 42: 361-364

Shimojo, M., K. Ikeda, Y. Asano, R. Ishiwaka, H. Sato, Y. Nakano, M. Tobisa, N. Ohba, M. Eguchi and Y. Masuda 2006 Introducing viewpoints of mechanics into basic growth analysis - (I) Three aspects of growth mechanics compared with three laws of motion -. J. Fac. Agr., Kyushu Univ., 51 285-287

Shimojo, M., K. Ikeda, Y. Asano, R. Ishiwaka, H. Sato, Y. Nakano, M. Tobisa, N. Ohba, M. Eguchi and Y. Masuda $2007 a$ Introducing viewpoints of mechanics into basic growth analysis - (III) Applying growth force and leaf-light complex to production and digestion analyses of forages -. J. Fac. Agr. Kyushu Univ., 52: 69-72

Shimojo, M., Y. Asano, R. Ishiwaka, H. Sato, Y. Nakano, M. Tobisa, N. Ohba, M. Eguchi and Y. Masuda 2007b Introducing viewpoints of mechanics into basic growth analysis- (VI) Some solutions to a simple differential equation associated with growth mechanics -. J. Fac. Agr., Kyushu Univ., 52 361-365

Shimojo, M., T. Shao and Y. Masuda 2008 Introducing viewpoints of mechanics into basic growth analysis - (VII) Mathematical properties of basic growth mechanics in ruminant -. J. Fac. Agr., Kyushu Univ., 53: 453-458

Watson, D. J. 1952 The physiological basis of variation in yield Adv. Agron., 4: 101-145 